\title{
Extracellular Glucose Concentration in Mammalian Brain: Continuous Monitoring of Changes during Increased Neuronal Activity and upon Limitation in Oxygen Supply in Normo-, Hypo-, and Hyperglycemic Animals
}

\author{
Ian A. Silver ${ }^{1}$ and Maria Erecińska² \\ 'Department of Anatomy, School of Veterinary Science, University of Bristol, Bristol, BS2 8EJ, United Kingdom and \\ 2Department of Pharmacology, University of Pennsylvania, Philadelphia, Pennsylvania 19104
}

\begin{abstract}
The concentration of extracellular glucose in anesthetized rat brain was measured continuously with two types of substrate-specific microelectrodes in a number of physiological and pathological conditions. Extracellular glucose level increased in hyperglycemia and decreased in hypoglycemia, paralleling the changes in blood sugar. Increased neuronal activity and in particular spreading depression, evoked triphasic alterations in extracellular glucose concentration: an initial rapid fall was followed by an equally swift overshoot above the baseline and a subsequent return to it. Limitation in $\mathrm{O}_{2}$ supply led to a decline in extracellular content of glucose: respiration with $5 \% \mathrm{O}_{2}$ reduced the level by $7-20 \%$ and that with $3 \% \mathrm{O}_{2}$ by $75-85 \%$. Decreases to undetectable concentrations were seen in ischemia despite the use of an oxygen-insensitive microglucose sensor. Restoration of oxygen supply to the brain was accompanied by increases in extracellular glucose content above the original normoxic level, which returned to baseline values after 10-15 $\mathrm{min}$. In hyperglycemic animals ischemia-induced leakage of $\mathrm{K}^{+}$was delayed while the rate of recovery to control levels after restitution of blood flow was enhanced. It is concluded that continuous monitoring of glucose with glucose-specific microelectrodes provides a new and important insight into brain energy metabolism.
\end{abstract}

[Key words: glucose microelectrodes, brain glucose concentration, hypoglycemia, hyperglycemia, ischemia/hypoxia; external ion levels in brain]

The mammalian CNS relies on a constant supply of external glucose for its undisturbed operation. Under normal circumstances other fuels, such as fatty acids or ketone bodies, play only a very minor role (Siesjö, 1978) while endogenous stores of glycogen are relatively small and confined largely to astrocytes (Watanabe and Passonneau, 1973; Koizumi, 1974; Ibrahim, 1975; Cataldo and Broadwell, 1986; Sagar et al., 1987). Glucose is transported rapidly across the blood-brain barrier and plasma membranes, and it is generally accepted that its metabolism is phosphorylation rather than transport limited (Lund-Andersen,

\footnotetext{
Received Sept. 1, 1993; revised Feb. 7, 1994; accepted Feb. 24, 1994.

This work was supported by Grant NS 28329 from N1H.

Correspondence should be addressed to Dr. Maria Erecinska, Department of Pharmacology, University of Pennsylvania, School of Medicine, Philadelphia, PA 19104-6084.

Copyright (c) 1994 Society for Neuroscience $0270-6474 / 94 / 145068-09 \$ 05.00 / 0$
}

1979; Pardridge, 1983; Robinson and Rapoport, 1986; Furler et al., 1991). Thus, free glucose is present intracellularly. Measurements from several laboratories using biochemical assays on fixed tissue (see, e.g., Lowry et al., 1964; Tews et al., 1965; Duffy et al., 1972; Lewis et al., 1974a; Gjedde et al., 1981; Gjedde and Diemer, 1983; Evans and Meldrum, 1984) as well as noninvasive in vivo detection by NMR after infusion of ${ }^{13} \mathrm{C}$ glucose (Mason et al., 1992a) have shown that the average glucose content of rat brain is $2-4 \mu \mathrm{mol} / \mathrm{gm}$ wet weight at normoglycemic plasma concentrations (6-8 mM). Brain glucose levels fall in hypoglycemia (Tews et al., 1965; Lewis et al., 1974; Mason et al., 1992; for review, see Siesjö, 1978) and rise in hyperglycemia (Welsh et al., 1980; Mason et al., 1992) reflecting the fact that the $K_{m}$ values for glucose transport on the two predominant relevant transporters, GLUT-1 (located in blood-brain barrier) and GLUT-3 (plasma membranes), are rather high (Gould et al., 1991).

In spite of its cardinal role in cerebral metabolism and function, there is little information on the concentration of glucose and changes therein in the extracellular environment of brain. The finding that transport of glucose occurs via a Na-independent, facilitated diffusion (Crone, 1965; Lund-Andersen, 1979) implies that the external concentration must be at least as high, and under normal circumstances higher, than that inside the cell in order to provide the driving force for uptake. However, in a recent study using a microdialysis technique (Fellows et al., 1992) it was reported that the extracellular concentration of glucose in the CNS is only $0.47 \mathrm{~mm}$, which is on average sixfold lower than the total brain content.

The present study was designed to mcasure and continuously monitor changes in extracellular glucose concentrations using glucose microelectrodes. Measurements were made in normoxic rat brain when plasma glucose level was normal (normoglycemia) or altered by an injection of insulin (hypoglycemia) or a bolus of glucose (hyperglycemia). The effects of stimulated activity (including spreading depression) and limitations in oxygen supply (hypoxia and ischemia) on brain glucose concentrations were also investigated. To evaluate the role of glucose metabolism in cellular ion homeostasis, alterations in extracellular potassium and hydrogen ion concentrations $\left(\left[\mathrm{K}^{+}\right]_{c}\right.$ and $\left.\left[\mathrm{H}^{+}\right]_{c}\right)$ were monitored simultaneously in some experiments.

\section{Materials and Methods}

White Wistar rats of both sexes weighing 250-300 gm were anesthetized by intraperitoneal injection of pentobarbitone sodium $(60 \mathrm{mg} / \mathrm{kg}$ as a 
$6 \%$ solution in water; Abbott Laboratories Inc., Irving, TX) together with atropine sulfate $(0.3 \mathrm{mg} / \mathrm{kg}$; Roche Products, Ltd., Welwyn Garden City, Herts, UK). The body temperature was maintained constant at $38^{\circ} \mathrm{C}$ with a thermostatically controlled heating pad. Additional doses of anesthetic were given as required.

Surgical preparation. A tracheostomy was performed and the trachea intubated for later connection to an anesthetir apparatus supplying $30 \%$ $\mathrm{O}$, and $70 \% \mathrm{~N}, \mathrm{O}$. The tracheal cannula was kept free of secretions by periodic aspiration when necessary. Respiration was recorded via a pressure transducer and $\mathrm{CO}_{2}$ in the expired air was monitored with a Beckman infrared analyzer. Ärtificial respiration was carried out during ischemic and hypoxic episodes using a Harvard small animal respiratory pump.

The ventral caudal artery was cannulated for the collection of arterial samples and for recording blood pressure via a miniature Gould-Statham P50 physiological pressure transducer. A catheter was inserted into the left femoral vein for administration of fluids, collection of venous samples and return of blood from the caudal artery used for measurement of blood sugar (see below). The ventral aspect of the neck was incised; the vertebral arteries were exposed at the level of Ce6-7 and occluded bilaterally. The common carotid arteries were separated from the other structures in the carotid sheath and snared with linen thread which was brought to the ventral surface of the neck through 2 $\mathrm{mm}$ i.d. polyethylene tubes and secured loosely in bulldog clips, as described previously (Silver and Erecińska, 1990, 1992). The head of the animal was secured in a modified "Baltimore" stereotaxic head holder using the position described by de Groot (1959). ECoG was recorded from stainless steel miniature bone screws inserted into the frontal bones, and EKG activity was monitored continuously via subcutaneous needle electrodes from left and right forelimbs.

The skin over the top of the skull was incised and reflected and the brain exposed through 3-mm-diameter burr holes over the cingulate cortex on each side of the midline. The dura was removed and substratespecific, extracellular microelectrodes (tips $<1.0 \mu \mathrm{M}$ ) were inserted into the brain by means of micromanipulators. The electrodes were connected via appropriate preamplifiers to a Gould multichannel recorder.

Ischemia was induced by simultaneous compression of both carotid arterics by ligatures (the vertebral arteries having been occluded by diathermy as described above). Blood flow to the brain was restored by release of the same ligatures. The rats remained anesthetized throughout the postischemic recording period, during which monitoring of blood pressure, ECoG, heart rate, body temperature, and blood gas levels was maintained.

Hypoxia was produced by substituting $\mathrm{N}_{2}$ for the $\mathrm{N}_{2} / \mathrm{O}_{2}$ mixture in the respiratory pump. Hyperglycemia was induced by intraperitoneal injection of $0.5 \mathrm{gm}$ of glucose in $3 \mathrm{ml}$ of water and hypoglycemia by subcutaneous injection of insulin $(25 \mathrm{IU} / \mathrm{kg})$.

Spreading depression was provoked either by application of a cotton wick approximately $1 \mathrm{~mm}$ diameter soaked in $0.5 \mathrm{M} \mathrm{KCl}$ or by touching the cortex with a cold metal probe.

Recordings. Two types of glucose-sensitive microelectrodes were used. In normoxic brain needle electrodes slightly modified from those dcscribed by Gardiner and Silver (1979) were constructed by electrodeposition of platinum black on gold or platinum surfaces. The Pt-black was dipped into a $1 \%$ solution of glucose oxidase (Boehringer-Mannheim Corp., Indianapolis, IN), dried in air, and cross-linked to the metal by 10 sec exposure to $1 \%$ glutaraldehyde solution, after which the probes were washed in several changes of distilled water and air dried. The tips were then coated in four thin layers of cellulose diacetate, dried, and dipped into a $1 \%$ aqueous solution of ascorbate oxidase (BoehringerMannheim Corp.). Since the changes recorded in the present study were relatively slow, diffusion membranes were used on the glucose electrodes which eliminated stirring sensitivity and other diffusion related artefacts. Moreover, the covering of an electrode tip by a water-permeable membrane, within which the linear diffusion path of the substrate is confined to at least $95 \%$, virtually eliminates the effects of edema and small hematomas. After coating, the electrodes were air dried for storage in the dark and hydrated immediatcly beforc usc. These probes were polarized at $+0.6 \mathrm{~V}$ against a silver/silver chloride reference electrode and calibrated in standard solutions of $0,1,2,4,8,16$, and $32 \mathrm{~mm}$ glucose in $5 \%$ bovine serum albumin at $37^{\circ} \mathrm{C}$. Each electrode was tested for sensitivity to ascorbate by including ascorbic acid $(10 \mathrm{mg} / \mathrm{liter})$ in the $4 \mathrm{~mm}$ glucose solution. Electrodes that were sensitive to ascorbate gave readings above those expected for glucose at that concentration and were discarded. The current flowing from the electrodes was measured with a high-input impedance amplifier and was linear in respect of glucose concentration. A small residual "zero current" was always observed in the absence of glucose. The sensor is based on the reaction

$$
\text { glucose } \mathrm{O}_{2} \rightarrow \text { gluconic acid }+\mathrm{H}_{2} \mathrm{O}_{2}
$$

and the immediate electrolysis of the hydrogen peroxide to water and oxygen. Although the $K_{m}$ of glucose oxidase for oxygen is low, in severely hypoxic brain oxygen may become the limiting factor in the above reaction. Lack of oxygen causes the type of electrode described above to indicate that a lower concentration of glucose is present than may actually be the case.

In brain that was expected to become hypoxic at some stage the glucose electrodes used were of the type described by Cass et al. (1984), which involve using ferrocene as an electron acceptor by incorporating it onto the electrode surface. The performance of this electrode is linear within the range of glucose concentrations $0.1-40 \mathrm{~mm}$ and is insensitive to changes in oxygen concentration (Frew and Hill, 1987). Protection of the electrode surface by a relatively thick diffusion membrane and incorporation of ascorbate oxidase onto its surface largely eliminates possible errors due to interfering substances and variability in the diffusion pathway. The calibrations of ferrocene-based electrodes remained stable over many days in protein-containing test solutions at $37^{\circ} \mathrm{C}$.

Glucose microelectrodes in tissue recorded glucose concentrations in the extracellular space. In order to establish the relationship of the electrode measurements to those of glucose content of whole brain, in some experiments where histological reconstruction was not required, brain was flash frozen with liquid nitrogen in situ while electrode recordings were being made and the glucose content measured by standard biochemical technique. In the seven brains examined, the extracellular glucose content measured by the electrodes was within $5 \%$ of that measured for whole brain.

Blood glucose was measured in a small arteriovenous bypass system located between the caudal artery and the femoral vein. The blood flowed from the arterial catheter through a $1 \mathrm{~mm}$ channel in a siliconized miniature polycarbonate block that incorporated a flat-ended, glass insulated, glucose oxidase-ferrocene electrode. Blood samples $(40 \mu \mathrm{l})$ were collected at 15 min intervals into Beckman Microfuge capillary tubes. An aliquot of $20 \mu \mathrm{l}$ was centrifuged immediately and the plasma kept on ice at $0^{\circ} \mathrm{C}$ until analyzed for glucose content in a standard clinical hexokinase-based colorimetric system (Technico Instruments Corp., Tarrytown, NY) to check that the in-line electrode was functioning reliably. Total blood sugar was determined from the other $20 \mu$ l by the method of Trinder (1969) using an Instrumentation Laboratories (Warrington, (heshire, UK) pediatric blood-glucose analyzer.

Extracellular recording of single cell electrical activity. Output from $\mathrm{Pt}$-in-glass $\mathrm{H}_{2}$ clearance, $\mathrm{O}_{2}$ - or glucose-sensitive electrodes was divided so that one record was made through a capacity coupled amplifier that detected single- or multiple-cell electrical activity while the second connection was via a polarizing DC input with a pass band from DC to 2 $\mathrm{Hz}$.

Blood flow and oxygen measurements. Brain oxygen availability, extracellular $\mathrm{pH}$, and potassium concentration were measured with platinum needle electrodes and ion-sensitive micropipettes containing appropriate liquid ion sensors as described by Silver and Erecinska (1990). Changes in local blood flow were followed by hydrogen clearance using the $\mathrm{H}_{2}$-generating and detection system of Stosseck et al. (1974).

Statistical analysis. Data were treated by analysis of variance with post hoc $t$ test and the level of statistical significance is specified in the tables and text.

\section{Results}

\section{Performance of the glucose electrode}

Both types of glucose oxidase-based electrodes provided a linear output in relation to glucose concentration well beyond the range of values encountered in these experiments. However, these probes are sensitive not only to glucose but also to ascorbic acid, the presence of which gives a false high reading for glucose. The interference from ascorbic acid was eliminated by incorporation of ascorbate oxidase in the outer layer of the electrode membrane, consistent with the finding of Scheller et al. (Scheller et al., 1987). Limitation of oxygen supply in hypoxic tissue presents a greater problem since despite the low $K_{m}$ of glucose 
Table 1. Extracellular concentration of glucose in brain of anesthetized rats and corresponding levels in blood

\begin{tabular}{|c|c|c|c|c|c|c|}
\hline \multirow[b]{2}{*}{ Condition } & \multicolumn{2}{|c|}{ Normoglycemia } & \multicolumn{2}{|l|}{ Hyperglycemia } & \multicolumn{2}{|l|}{ Hypoglycemia } \\
\hline & Brain & Blood & Brain & Blood & Brain & Blood \\
\hline Control & $2.4 \pm 0.1$ & $7.6 \pm 0.3$ & $4.5 \pm 0.4^{b}$ & $15.2 \pm 2.4$ & $0.16 \pm 0.03^{b}$ & $2.8 \pm 0.8$ \\
\hline \multicolumn{7}{|l|}{ Ischemia } \\
\hline $2 \mathrm{~min}$ & $0.3 \pm 0.1^{a}$ & $10 \pm 1.8$ & $1.9+0.4^{a . b}$ & $15.8+3.1$ & $0.03 \pm 0.0^{a, b}$ & $2.4 \pm 0.1$ \\
\hline $4 \mathrm{~min}$ & $0.05 \pm 0.04^{a}$ & & $0.16 \pm 0.10^{a, b}$ & & $0.0^{a}$ & \\
\hline $6 \mathrm{~min}$ & $0.0^{a}$ & & $0.0^{a}$ & & $0.0^{a}$ & \\
\hline $8 \min$ & $0.0^{a}$ & & $0.0^{a}$ & & $0.0^{a}$ & \\
\hline \multicolumn{7}{|l|}{ Recovery } \\
\hline $2 \min$ & $6.0 \pm 1.3^{a}$ & $11.0 \pm 2.1$ & $8.1 \pm 2.6^{a . b}$ & $15.6 \pm 4.1$ & $0.09 \pm 0.02^{u}$ & $2.3 \pm 0.1$ \\
\hline $4 \min$ & $8.5 \pm 2.0^{a}$ & $11.3 \pm 2.1$ & $10.5 \pm 3.2^{a, b}$ & $14.9 \pm 3.1$ & $0.15 \pm 0.03^{b}$ & $2.2 \pm 0.1$ \\
\hline $6 \mathrm{~min}$ & $6.4 \pm 1.6^{a}$ & $8.5 \pm 1.3$ & $8.8 \pm 3.3^{a, b}$ & $14.8 \pm 3.7$ & $0.17 \pm 0.03^{b}$ & $2.4 \pm 0.1$ \\
\hline $8 \mathrm{~min}$ & $4.7 \pm 0.9^{a}$ & $7.7 \pm 1.6$ & $7.1 \pm 2.7^{a, b}$ & $14.8 \pm 3.7$ & $0.17 \pm 0.02^{b}$ & $2.3 \pm 0.1$ \\
\hline $10 \mathrm{~min}$ & $3.5 \pm 0.9^{a}$ & $7.3 \pm 1.8$ & $5.8 \pm 1.5^{a, b}$ & $13.9 \pm 2.9$ & $0.14 \pm 0.01^{a, b}$ & $2.4 \pm 0.0$ \\
\hline $15 \mathrm{~min}$ & $2.6 \pm 0.4$ & $7.1 \pm 0.5$ & $4.3 \pm 1.0^{b}$ & $13.3 \pm 2.7$ & $0.13 \pm 0.02^{a, b}$ & $2.3 \pm 0.0$ \\
\hline
\end{tabular}

Brain glucose concentrations were measured with microelectrodes and those in blood either with a microelectrode or by an enzymatic method. All values are millimolar and represent means \pm SD of results in 40 normoglycemic, 30 hyperglycemic, and 34 hypoglycemic rats.

"Statistically significant with respect to control.

"Statistically significant with respect to normoglycemia $(p<0.05$ or better).

oxidase of oxygen, oxygen becomes the limiting factor in electrode output in severe ischemia or hypoxia. However, the nonoxygen dependent glucose-oxidase-ferrocene coupled system proved to be satisfactorily linear in hypoxic tissue in vivo.

\section{Extracellular concentration of glucose in rat brain}

The concentration of glucose in the extracellular space of rat brain was measured in normo-, hyper-, and hypoglycemic animals. The values are summarized as Control in Table 1. In normoglycemic rats, in which blood glucose level was $7.6 \pm 0.3$ $\mathrm{mm}$, that in the brain was $2.4 \pm 0.13 \mathrm{~mm}$. Upon an intraperitoneal bolus injection of $0.5 \mathrm{gm}$ of glucose, blood sugar level rose to $15.2 \pm 2.4 \mathrm{~mm}$ in about $10 \mathrm{~min}$; this was accompanied by an increase in the cerebral glucose content to $4.5 \pm 0.35 \mathrm{~mm}$. Hypoglycemia induced by administration of insulin lowered blood sugar concentration to $2.8+0.8 \mathrm{~mm}$ and brain concentration to $0.16 \pm 0.03 \mathrm{~mm}$. There were no significant differences in the levels of glucose between the anterior hypothalamus on the one hand and in the various regions of the cortex where the majority of measurements were made.

\section{Effect of increased activity on extracellular glucose concentration}

Stimulation of electrical activity in a single cell by touch or pressure on the sensory input from the tail or foot and recorded via the metal needle electrodes, caused no noticeable changes in the extracellular glucose concentration, although it was almost impossible to determine how close to a driven neuron a microelectrode was situated. However, when a microelectrode tip was fortuitously located among a group of cells that were activated simultaneously, small and transient falls in the sugar level were recorded, which usually did not exceed $0.1-0.2 \mathrm{~mm}$. The falls were followed by overshoots of similar magnitude above the baseline value before return to the control level. Much larger and very reproducible changes were seen upon induction of a wave of spreading depression (Fig. 1). Within a few seconds of application of $\mathrm{KCl}$, extracellular glucose concentration declined from $2.4 \mathrm{~mm}$ to $1.95 \mathrm{~mm}$ in less than $1 \mathrm{~min}$ and then abruptly rose to about $2.9 \mathrm{~mm}$. During the next 2-3 min, a gradual return to the baseline sugar concentration was observed.

These triphasic alterations in the level of extracellular glucose were also seen in brains of hyperglycemic animals although the initial fall and later overshoot were numerically smaller (Fig. 1).

\section{The effects of hypoxia on brain glucose concentration}

The effect of hypoxia on changes in cerebral extracellular concentration of glucose were investigated in normoglycemic animals in which the content of oxygen in the inspired air was lowered to $10 \%, 5 \%$, or $3 \%$. Mean arterial blood pressure and blood glucose level as well as brain oxygen tension were measured simultaneously. There were no alterations in [glucose] in brains of animals inspired at $10 \% \mathrm{O}_{2}$ but a fall of $7-20 \%$ was noted with $5 \%$ oxygen when brain partial pressure of oxygen $\left(\mathrm{pO}_{2}\right)$ was reduced almost to zero. With $3 \%$ oxygen marked alterations were observed (Fig. 2). Blood glucose concentration rose transiently to $9.5 \mathrm{~mm}$ and blood pressure declined by about $20 \mathrm{~mm} \mathrm{Hg}$ and then gradually rose toward the control value. Brain $\mathrm{pO}_{2}$ fell almost instantaneously to 0 , as measured with an oxygen microelectrode. Brain glucose decreased to a level less than $0.5 \mathrm{~mm}$ in about $1 \mathrm{~min}$.

When after $4 \mathrm{~min}$ the animals were returned to respiration with the usual $30 \%$ oxygen in $\mathrm{N}_{2}$, arterial blood pressure normalized, brain oxygen tension rose far beyond the control value as did the extracellular glucose concentration. Both the $\mathrm{pO}_{2}$ and glucose level returned in parallel to the baseline level in 4-5 min (Fig. 2).

Changes in extracellular glucose concentration in brains of normo-, hyper-, and hypoglycemic animals: correlation with $\left[\mathrm{K}^{+}\right]_{\mathrm{c}}$ and $\left[\mathrm{H}^{+}\right]_{\mathrm{c}}$ during ischemia and recovery therefrom

Alterations in [glucose], in brains of normo-, hyper-, and hypoglycemic animals were followed simultaneously with changes in cortical $\mathrm{pO}_{2},\left[\mathrm{~K}^{+}\right]_{\ell}$, and $\left[\mathrm{H}^{+}\right]_{e}$ during $10 \mathrm{~min}$ ischemia and 40 


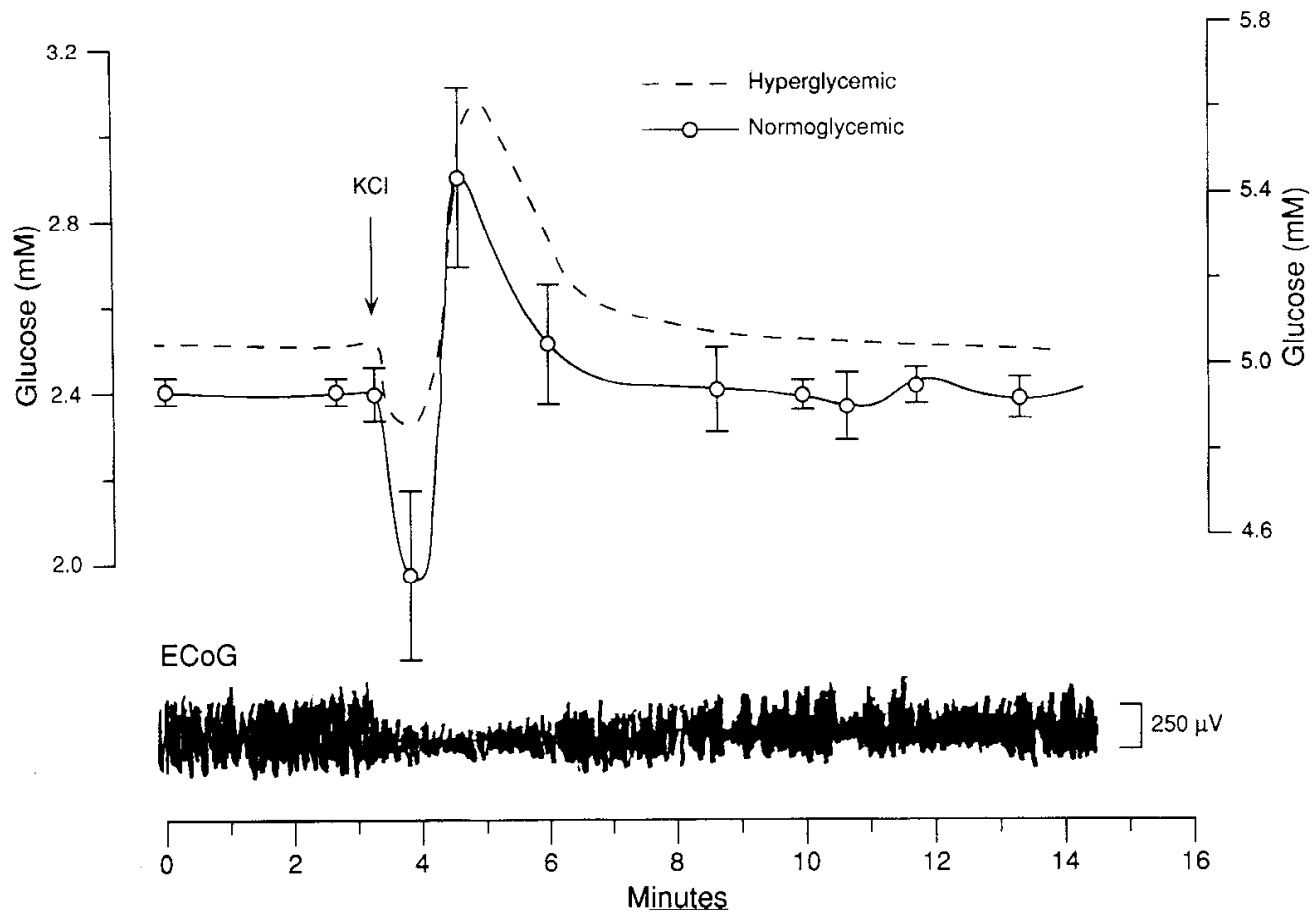

Figure 1. Composite figure compiled from two sets of nine records of glucose concentration changes $(x$-axis) in cerebral cortex during single waves of spreading depression in normoglycemic (solid line) and hyperglycemic (dashed line) rats. The scale for the normoglycemic recordings $(2.0-3.2 \mathrm{~mm})$ is shown on the left and that for the hyperglycemic animals $(4.6-5.8 \mathrm{~mm})$ on the right of the diagram. Recordings were made with microelectrodes that did not incorporate ferrocene. A typical ECoG trace is shown below. Note the smaller changes in the hyperglycemic trace. min recovery period. Examples of the continuous recordings are displayed in Figures 3-5 and results from a number of experiments are summarized in Tables 1 and 2. The following points can be made. (1) The fastest event which followed carotid compression was the decline in oxygen tension. (2) Ischemia led to a rapid fall in external concentration of glucose in all animals (Table 1). The numerical values recorded within the first $2 \mathrm{~min}$ were highest in hyper- and lowest in hypoglycemic animals, as expected. However, after 3-4 min of ischemia, extracellular glucose concentration in brain, as measured with the microelectrode, was close to 0 in all animals. (3) $\left[\mathrm{K}^{+}\right]$, rose and $\mathrm{pH}_{\text {c }}$ fell during periods of oxygen deprivation. Changes in potassium concentration were fastest in hypoglycemic and slowest in hypcrglycemic animals, although after $10 \mathrm{~min}$ there is no statistical difference in $\left[\mathrm{K}^{+}\right]$, among the three groups. The largest and fastest decline in extracellular $\mathrm{pH}$ was seen in hyperglycemic

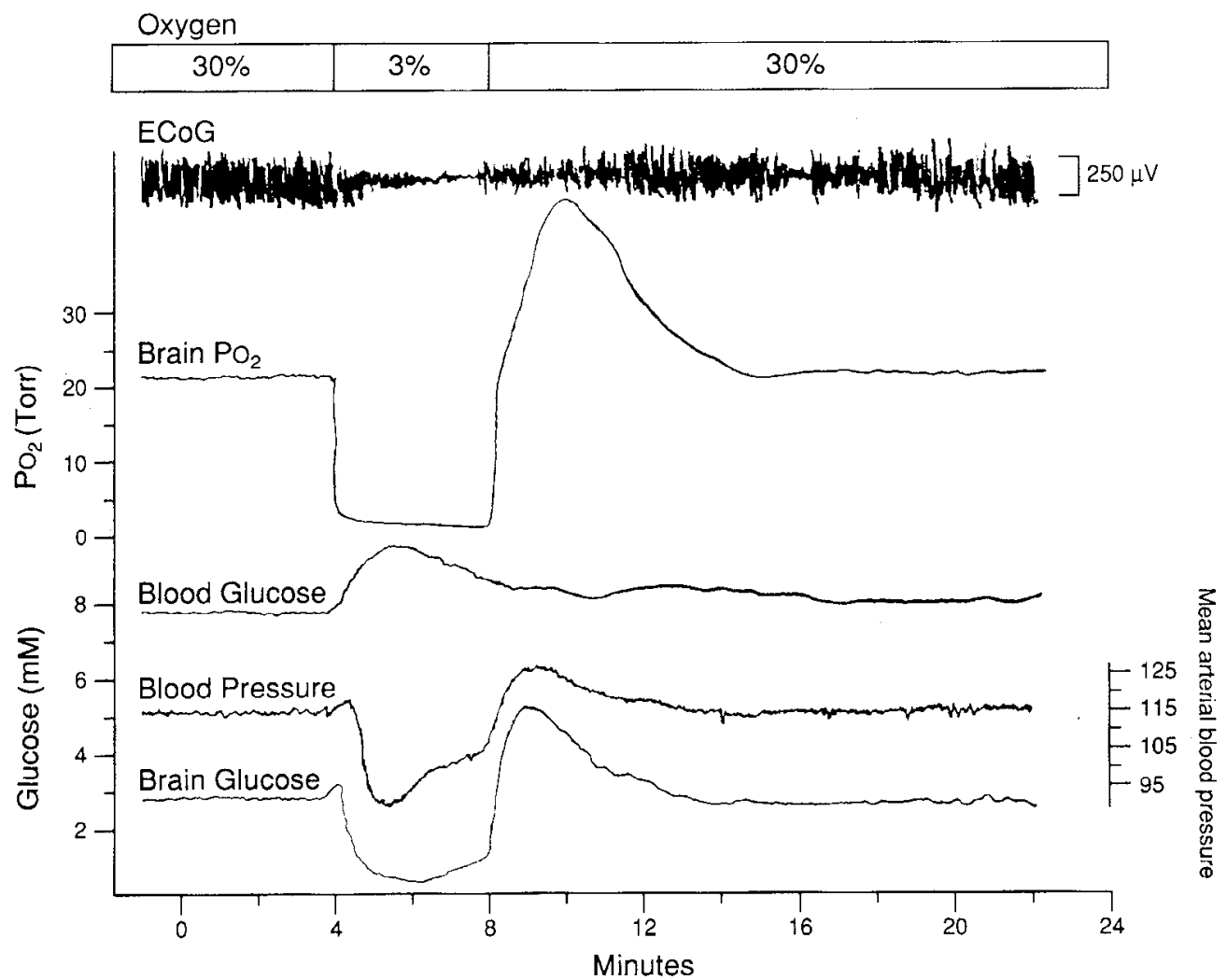

Figure 2. Simultaneous traces of ECoG, oxygen availability $\left(P_{2}\right)$, blood glucose, mean arterial blood pressure, and brain glucose in an anesthetized rat. The glucose electrodes were made with ferrocene as the electron acceptor. The concentrations of oxygen supplied to the rat are shown as percentages at the $t o p$ of the chart, the balance of gas being nitrogen. All other measurements are as described in the text. 
Figure 3. Simultaneous records of ECoG, oxygen availability $\left(\mathrm{PO}_{2}\right)$, cortical pH ( $p H$ Brain Tissue), blood glucose concentration and extracellular brain glucose in a normoglycemic rat, before, during, and after a global cerebral ischemic episode caused by bilateral carotid compression. The glucose electrodes used for the recordings incorporated ferrocene.

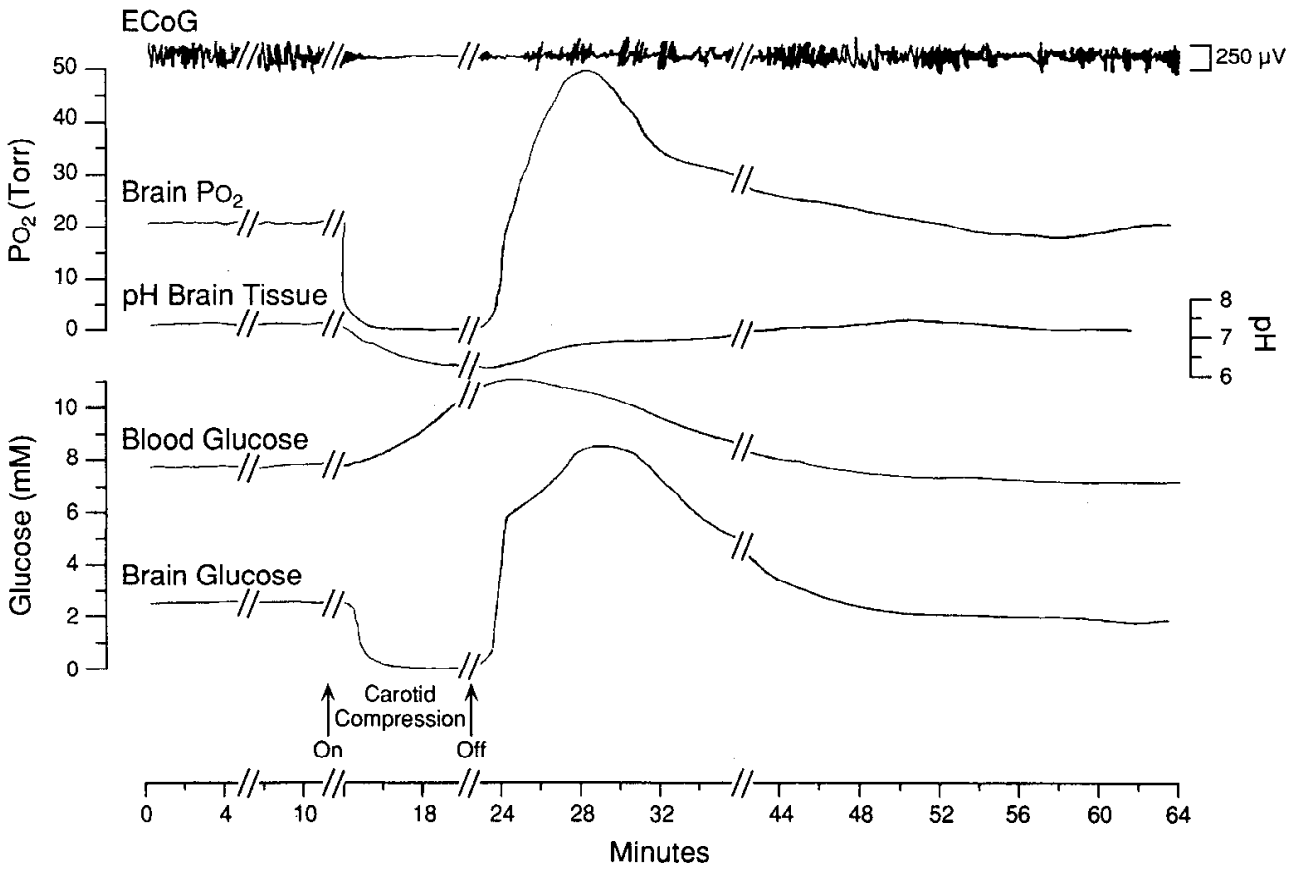

animals and the slowest in hypoglycemic rats. After $10 \mathrm{~min}$ of ischemia changes in $\mathrm{pH}_{c}$ among the three groups were still statistically significant. (4) The recovery of brain $\mathrm{pO}_{2}$ and extracellular content of glucose from ischemia resembled that after hypoxia: both the oxygen tension and the sugar level rose swiftly and almost in parallel beyond their respective baseline values and returned to a 'control' state after about $15 \mathrm{~min}$. (5) $\left[\mathrm{K}^{+}\right]_{e}$ normalized fastest in brains of hyperglycemic rats and slowest in those from hypoglycemic animals. Cerebral $\mathrm{pH}_{4}$, recovered most rapidly in normoglycemic animals. In brains of rats with high blood sugar levels the recovery was slowed but complete within $15 \mathrm{~min}$ whereas in hypoglycemia it appeared to be longer delayed. (6) In animals given insulin, the fall in brain glucose was accompanied by a rise in brain $\mathrm{pO}_{2}$ (Fig. 5).

\section{Discussion}

The results summarized in this work offer the first systematic evaluation of changes in the extracellular concentration of glucose in the CNS under a variety of physiological and pathological conditions. The study utilizes microelectrode technology that has the advantage over biochemical assays in that it allows continuous monitoring of changes over a period of time in the same animal. Although this is not the first attempt to measure external glucose in brain, earlier investigations with microelec-
Figure 4. Simultaneous records of ECoG, brain oxygen availability (Brain $P O_{2}$ ), blood glucose concentration, and extracellular glucose levels in brain cortex (brain glucose) before and after intraperitoneal injection of $0.5 \mathrm{gm}$ of glucose in $3 \mathrm{ml}$ of water. The glucose electrodes were made with ferrocene. After establishment of hyperglycemia an ischemic episode was induced by bilateral carotid compression $(\mathrm{On})$. Cerebral blood supply was restored $(\mathrm{Ca}$ rotid Compression Off) after $8 \mathrm{~min}$.

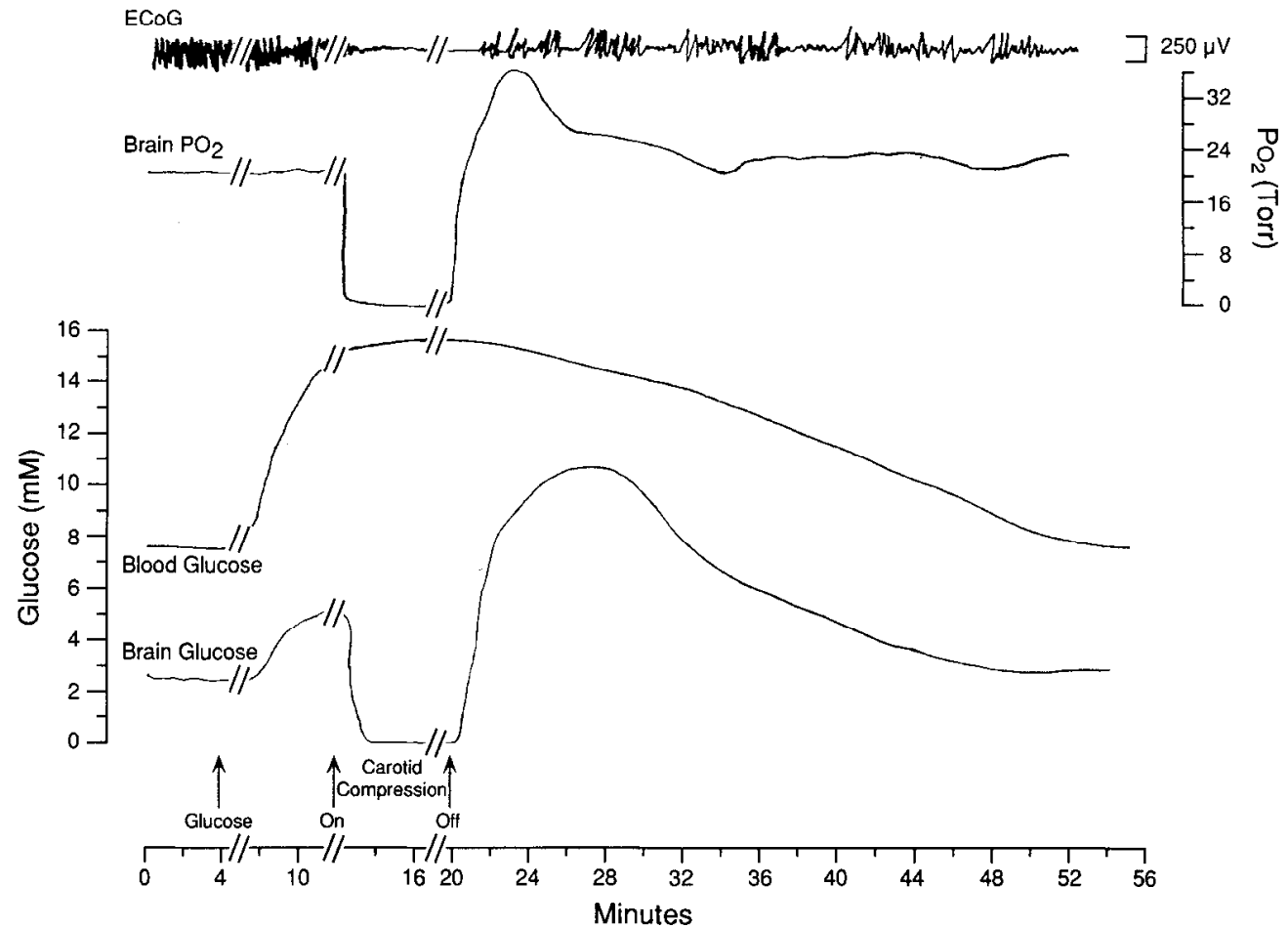




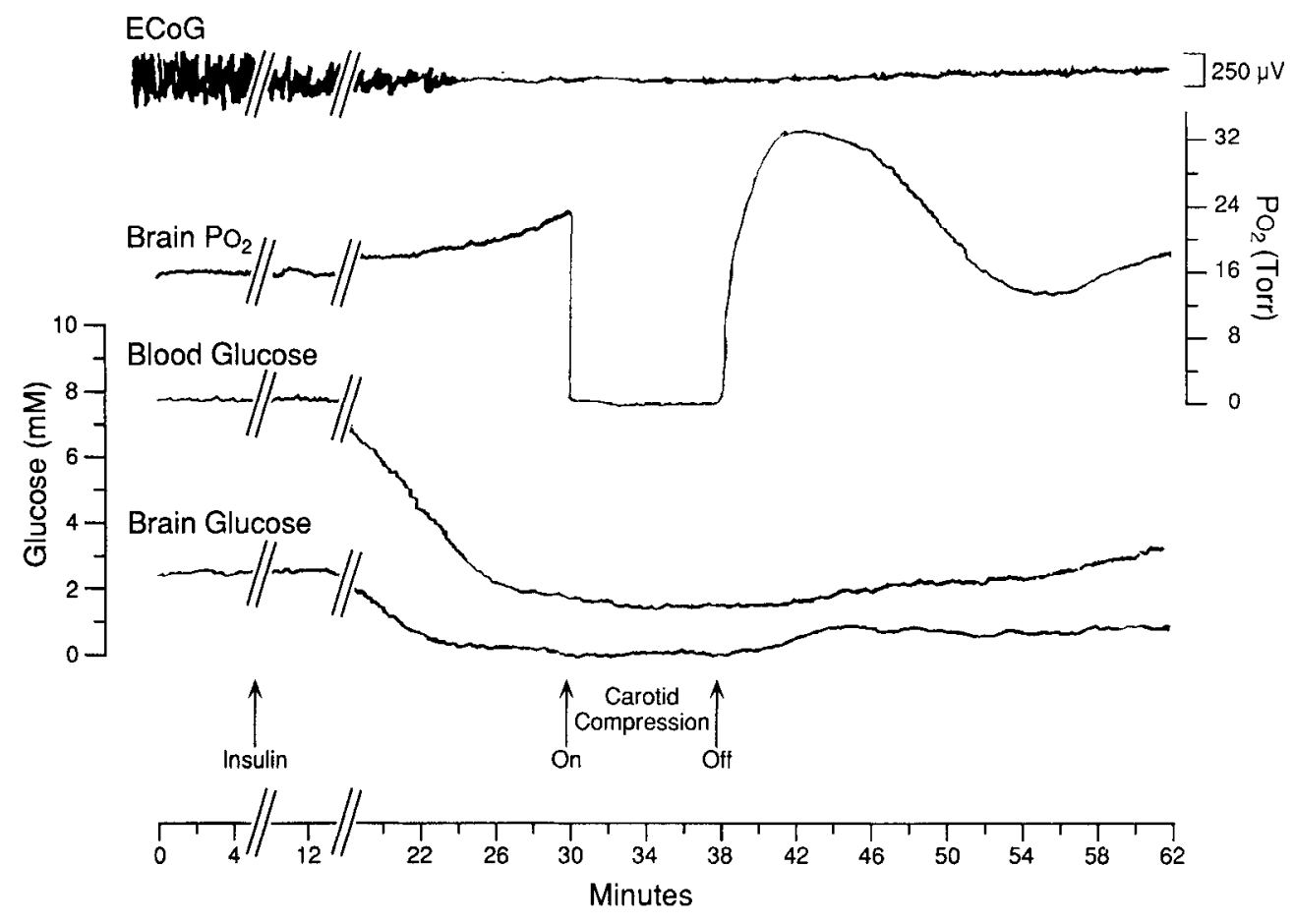

Figure 5. Simultaneous records of ECoG, brain oxygen availability (Brain $P_{O_{2}}$ ), blood glucose concentration, and brain glucose level before and during hypoglycemia induced by subcutaneous injection of insulin $(25 \mathrm{IU} / \mathrm{kg})$. After establishment of hypoglycemia a global cerebral ischemic episode was induced by bilateral carotid occlusion (Carotid Compression $O n$ ) for $8 \mathrm{~min}$. Ferrocene-type glucose electrodes were used. trodes either were of a preliminary nature (Silver, 1976) or did not yield any quantitative data (Boutelle et al., 1986). More recently the technology has been combined with intracerebral microdialysis and changes quantified indirectly, after a correction for recoveries of the sugar in the dialysates (Fellows et al., 1992). For reasons that we cannot explain, this approach yielded severalfold lower values for extracellular concentration of glucose $(0.47 \mathrm{~mm})$ than the measurements reported here (and that utilized an apparently identical technology) as well as any estimates of total brain glucose reported in the literature (Lowry et al., 1964; Tews et al., 1965; Duffy et al., 1972; Lewis et al., 1974; Gjedde et al., 1981; Gjedde and Diemer, 1983; Evans and Meldrum, 1984; Mason et al., 1992). Another attempt aimed at on-line monitoring of cerebral extracellular glucose concentration used the microdialysis technique combined with an NADPH-linked enzymatic assay for the sugar; however, this study provided only qualitative results (van der Kuil and Korf, 1991).

The values for the extracellular concentration of glucose in brains from normo-, hyper-, and hypoglycemic rats determined in the current work (Table 1) are very close to the figures for the total tissue levels obtained by others under comparable conditions (see above). Interestingly, our numbers are particularly close to those produced by NMR (Mason et al., 1992) which, like microelectrode technology, does not require prior tissue fixation for generation of the results. Because the overwhelming proportion of the CNS volume, about $85 \%$, is occupied by cells, the similarity in the extracellular glucose concentration and that in whole brain means that there are no major gradients in this sugar across the plasma membrane.

Extracellular concentration of glucose is the product of the rate of sugar delivery from capillaries across the blood-brain barrier and the rate of utilization by cells. It is well known that there is close coupling in the CNS between the two processes and that the velocity of influx exceeds that of phosphorylation (Cremer et al., 1981; Hawkins et al., 1983; Cunningham et al.,
1986; Robinson and Rapoport, 1986; Furler et al., 1991). Consequently, intracellular glucose metabolism can remain constant in spite of a decrease in blood sugar concentration until transport becomes limiting. This usually occurs at plasma levels of 2.5 mM and lower (Norberg and Siesjö, 1976; Ghajar et al., 1982; Robinson and Rapoport, 1986; Pelligrino et al., 1990). Our results show that extracellular glucose concentration in brain changes in a number of physiological and pathological situations. Increase in neuronal firing, such as occurs during electrical stimulation, reduces glucose level in the external environment, most likely due to enhanced utilization by cells (Shinohara et al., 1979; Sokoloff, 1981; Kocher, 1990). Aerobic spreading depression also decreases extracellular concentration of the sugar because elevated ion pumping consumes more energy. These observations are consistent with data obtained on whole brain, which record a fall in tissue glucose content under similar conditions (Krivánek, 1961; Gjedde et al., 1981; Evans and Meldrum, 1984; Lauritzen et al., 1990). However, a fall in brain glucose level must activate homeostatic mechanisms, such as increase in blood flow (Leão, 1944; Van Harreveld and Ochs, 1957; Leniger-Follert and Hossmann, 1979) and/or enhancement of transport (Gjedde et al., 1981), because the reduction is rapidly followed by a transient overshoot after which glucose level returns to the original value. Similar, albeit qualitative, observations were made in two other investigations that utilized cerebral microdialysis. In the first, it was shown that after electrically induced seizures (which should have increased metabolism) dialysate concentration of glucose in the hippocampus was increased transiently (van der Kuil and Korf, 1991). In the second, application of veratridine, which potently enhances neuronal firing and energy utilization, was found to decrease the extracellular glucose content as measured by microdialysis in conscious, freely moving rats (Fellows et al., 1992). It appcars that each of these studies recorded a different phase of the response measured by us directly in brain.

Respiration of rats with $3 \%$ oxygen induced an immediate 
Table 2. Extracellular concentration of potassium and protons $(\mathrm{pH})$ in the brains of normo-, hyper-, and hypoglycemic anesthetized rats during stop-flow ischemia and recovery

\begin{tabular}{|c|c|c|c|c|c|c|}
\hline \multirow[b]{2}{*}{ Condition } & \multicolumn{2}{|c|}{ Normoglycemia } & \multicolumn{2}{|c|}{ Hyperglycemia } & \multicolumn{2}{|l|}{ Hypoglycemia } \\
\hline & {$\left[\mathrm{K}^{+}\right]_{e}$} & $\mathrm{pH}$ & {$\left[\mathrm{K}^{+}\right]_{e}$} & $\mathrm{pH}$ & {$\left[\mathrm{K}^{+}\right]_{e}$} & $\mathrm{pH}$ \\
\hline Control & $\begin{array}{l}3.30 \pm 0.10 \\
(73)\end{array}$ & $\begin{array}{l}7.34 \pm 0.02 \\
(34)\end{array}$ & $\begin{array}{l}3.30 \pm 0.10 \\
(41)\end{array}$ & $\begin{array}{l}7.35 \pm 0.08 \\
(38)\end{array}$ & $\begin{array}{l}3.50 \pm 0.32 \\
(47)\end{array}$ & $\begin{array}{l}7.30 \pm 0.11 \\
(34)\end{array}$ \\
\hline \multicolumn{7}{|l|}{ Ischemia } \\
\hline $2 \min$ & $6.35 \pm 0.70^{a}$ & $7.01 \pm 0.11^{a}$ & $3.50 \pm 0.30$ & $6.90 \pm 0.13^{a, b}$ & $13.8 \pm 7.3^{a}$ & $7.00 \pm 0.12^{a}$ \\
\hline $4 \mathrm{~min}$ & $59.4 \pm 12.5^{a}$ & & $47.6 \pm 9.0^{a, b}$ & & $67.0 \pm 8.3^{a, b}$ & \\
\hline $10 \mathrm{~min}$ & $\begin{array}{l}75.3 \pm 8.6^{a} \\
(28)\end{array}$ & $\begin{array}{l}6.30 \pm 0.33^{a} \\
(28)\end{array}$ & $\begin{array}{l}73.2 \pm 7.9^{a} \\
(27)\end{array}$ & $\begin{array}{l}6.11 \pm 0.21^{a, b} \\
(23)\end{array}$ & $\begin{array}{l}78.7 \pm 5.3^{a} \\
(29)\end{array}$ & $\begin{array}{l}6.43 \pm 0.15^{a} \\
(25)\end{array}$ \\
\hline \multicolumn{7}{|l|}{ Recovery } \\
\hline $2 \min$ & $16.2 \pm 7.4^{a}$ & $7.15 \pm 0.15^{a}$ & $10.2 \pm 3.1^{a, b}$ & $6.92 \pm 0.13^{a, b}$ & $27.5 \pm 7.1^{a}$ & $7.11 \pm 0.23^{a}$ \\
\hline $10 \mathrm{~min}$ & $3.04 \perp 0.15$ & $7.28 \perp 0.13$ & $3.50 \perp 0.15^{b}$ & $7.21 \perp 0.08^{a, b}$ & $5.9 \pm 1.5^{a}$ & $7.18 \pm 0.18^{a}$ \\
\hline $15 \mathrm{~min}$ & $\begin{array}{l}3.54 \pm 0.15 \\
(24)\end{array}$ & $\begin{array}{l}7.31 \pm 0.11 \\
(27)\end{array}$ & $\begin{array}{l}3.30 \pm 0.11 \\
(25)\end{array}$ & $\begin{array}{l}7.32 \pm 0.13 \\
(21)\end{array}$ & $\begin{array}{l}3.80 \pm 0.57 \\
(29)\end{array}$ & $\begin{array}{l}7.22 \pm 0.13^{a} \\
(24)\end{array}$ \\
\hline
\end{tabular}

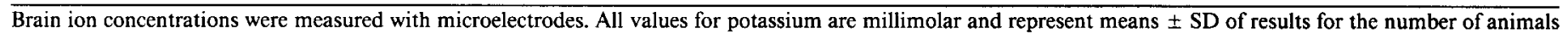
in parentheses.

"Statistically significant with respect to control.

"Statistically significant with respect to normoglycemia ( $p<0.05$ or less).

decrease in extracellular concentration of glucose to a very low level, in spite of a rise in blood sugar level (Fig. 2). This behavior was somewhat unexpected because Duffy et al. (1972) did not note any reduction in brain glucose content when mice (anesthetized or not) were allowed to breathe $4 \%$ oxygen for $15 \mathrm{~min}$; even during respiration with zero oxygen a $50 \%$ reduction required almost a minute. This diversity in sensitivity to a limitation in oxygen supply may be due to species differences. Notwithstanding, our observation implies that under such conditions either glucose utilization by cells is markedly increased or transport is decreased, or both occur simultaneously. Increased carbohydrate metabolism via anaerobic glycolysis with generation of lactate is a well-known phenomenon that accompanies tissue hypoxia (Siesjö, 1978). However, it has also been reported that anoxia impairs unidirectional transport of glucose (Betz et al., 1974). This suggests that in spite of a rise in plasma sugar content and an increase in cerebral blood flow glycolysis may be substrate-limited during severe hypoxia.

In our experiments ischemia led to a rapid decrease in extracellular glucose concentration consistent with many studies on whole brain that show rapid depletion of tissue carbohydrate stores under such conditions (Lowry et al., 1964; Duffy et al., 1972; Ljunggren et al., 1974; for review, see Siesjö, 1978). We have also confirmed earlier data in the literature that hyperglycemia decreases the rate of ischemic potassium leakage from cells but increases the rate of external acidification, whereas hypoglycemia has an opposite effect on both parameters (Branston et al., 1978; Siemkowicz and Hansen, 1981; Ekholm et al., 1993). The delay in $\mathrm{K}^{+}$leakage during hyperglycemia is, most likely, caused by better preservation of cellular ATP level, which takes longer to decline when brain glucose content is higher (Ekholm et al., 1993). In our hands, hyperglycemia accelerates whereas hypoglycemia diminishes the rate of $\left[\mathrm{K}^{+}\right]_{e}$ normalization after periods of oxygen deprivation. This behavior, which is at variance with an earlier study in which no effect of hyperglycemia on ion recovery was reported (Siemkowicz and Hansen, 1981), was consistently observed in all our experiments on a relatively large number of animals. Moreover, a similar effect of high external glucose concentration has been noted in ex- periments on brain slices (Schurr et al., 1987; Roberts and Sick, 1992). Although external potassium concentration may recover faster in the presence of high cerebral glucose content, this does not appear to be related in any beneficial way to normalization of metabolism because it has been found that hyperglycemia impairs postischemic recovery of the energy level (Welsh et al., 1980) and depresses cerebral metabolic rate (Siemkowicz et al., 1982).

Our study shows that in the immediate postischemic/posthypoxic period there is a transient increase in extracellular glucose level in brains of anesthetized animals, although blood glucose concentrations may be falling under the same conditions. Interestingly, the pattern of changes in glucose under these conditions follows very closely that in brain $\mathrm{pO}_{2}$. This suggests that increase in blood flow and consequent hyperemia (Pulsinelli et al., 1982) may be responsible for both phenomena. Decreases in metabolic rate and in utilization of glucose reported by previous authors (Pulsinelli et al., 1982) usually occur late in postischemic recovery. Nevertheless, it is also possible that in the very early stage of reperfusion, lactate that has accumulated in the tissue during hypoxia/ischemia is metabolized by cells in addition to glucose.

Another interesting observation in this study is that in hypoglycemia, when external glucose level in brain begins to fall, that of oxygen rises. This finding is consistent with these observations in the literature which noted that cerebral oxygen consumption during hypoglycemia is lower than in normoglycemia (Ghajar et al., 1982; but see Norberg and Siesjö, 1976, and Agardh et al., 1981, for contrary findings) while oxygen supply is simultaneously elevated through an increase in blood flow (see, e.g., Abdul-Rahman et al., 1980; Bryan et al., 1987; Breier et al., 1993).

\section{References}

Abdul-Rahman A, Agardh CD, Siesjö BK (1980) Local cerebral blood flow in the rat during severe hypoglycemia and in the recovery period following glucose injection. Acta Physiol Scand 109:307-314.

Agardh C-D, Chapman AG, Nilsson B, Siesjö BK (1981) Endogenous substrates utilized by rat brain in severe insulin-induced hypoglycemia. J Neurochem 36:490-500. 
Betz AL, Gilboe DD, Drewes LR (1974) Effects of anoxia on net uptake and unidirectional transport of glucose into the isolated dog brain. Brain Res 67:307-316.

Boutelle MG, Stanford C, Fillenz M, Albery WJ, Bartlett PN (1986) An amperometric enzyme electrode for monitoring brain glucose in the freely moving rat. Neurosci Lett 72:283-288.

Branston NM, Symon L, Strong AJ, Hope DT (1978) Measurements of regional cortical blood flow during changes in extracellular potassium activity evoked by direct cortical stimulation in the primate. Exp Neurol 59:243-253.

Breier A, Crane AM, Kennedy C, Sokoloff L (1993) The effects of pharmacologic doses of 2-deoxy-D-glucose on local cerebral blood flow in the awake, unrestrained rat. Brain Res 618:277-283.

Bryan RM, Hollinger BR, Keefer KA, Rage RB (1987) Regional cerebral and neural lobe blood flow during insulin-induced hypoglycemia in unanesthetized rats. J Cereb Blood Flow Metab 7:96-102.

Cass AEG, Davis G, Francis GD, Hill HAO, Aston WJ, Higgins IJ, Plotkin EV, Scott LDL, Turner APF (1984) Ferrocene-mediated enzyme electrode for amperometric determination of glucose. Anal Chem 56:667-671.

Cataldo AM, Broadwell RD (1986) Cytochemical identification of cerebral glycogen and glucose-6-phosphate activity under normal and experimental conditions. I. Neurons and glia. J Electron Microsc Techn 3:413-437.

Cremer JE, Ray DE, Sarna GS, Cunningham VJ (1981) A study of the kinetic behaviour of glucose based on simultaneous estimates of influx and phosphorylation in brain regions of rats in different physiological states. Brain Res 221:331-342.

Crone C (1965) Facilitated transfer of glucose from blood into brain tissue. J Physiol (Lond) 181:103-113.

Cunningham VJ, Hargreaves RJ, Pelling D, Moorhouse SR (1986) Regional blood-brain glucose transfer in the rat: a novel doublemembrane kinetic analysis. J Cereb Blood Flow Metab 6:305-314.

de Groot J (1959) The rat forebrain in stereotaxic co-ordinates. Verh K Ned Akad Wet AFD Natuurkd Tweed Reeks 52:1-49.

Duffy TE, Nelson SR, Lowry OH (1972) Cerebral carbohydrate metabolism during acute hypoxia and recovery. J Neurochem 19:959977.

Ekholm A, Katsura K, Siesjö BK (1993) Coupling of energy failure and dissipative $\mathrm{K}^{+}$fluxes during ischemia: role of preischemic plasma glucose concentration. J Cereb Blood Flow Metab 13:193-200.

Evans ME, Meldrum BS (1984) Regional brain glucose metabolism in chemically-induced seizures in the rat. Brain Res 297:235-245.

Fellows LK, Boutelle MG, Fillenz M (1992) Extracellular brain glucose levels reflect local neuronal activity: a microdialysis study in awake, freely moving rats. J Neurochem 59:2141-2147.

Frew JE, Hill HAO (1987) Electron-transfer biosensors. Philos Trans R Soc Lond [Biol] 316:95-106.

Furler SM, Jenkins AB, Storlien LH, Kraegen EW (1991) In vivo location of the rate-limiting step of hexose uptake in muscle and brain tissue of rats. Am J Physiol 261:E337-E347.

Gardiner RM, Silver IA (1979) A simple polarographic glucose sensor. J Physiol (Lond) 295:6P.

Ghajar JBG, Plum F, Duffy TE (1982) Cerebral oxidative metabolism and blood flow during acute hypoglycemia and recovery in unanesthetized rats. J Neurochem 38:397-409.

Gjedde A, Diemer NH (1983) Autoradiographic determination of regional brain glucose content. J Cereb Blood Flow Metab 3:303310.

Gjedde A, Hansen AJ, Quistorff B (1981) Blood-brain glucose transfer in spreading depression. J Neurochem 37:807-812.

Gould GW, Thomas HM, Jess TJ, Bell GI (1991) Expression of human glucose transporters in Xenopus oocytes: kinetic characterization and substrate specificities of the erythrocyte, liver, and brain isoforms. Biochemistry 30:5139-5145.

Hawkins RA, Mans AM, Davis DW, Hibbard LS, Lu DM (1983) Glucose availability to individual cerebral structures is correlated to glucose metabolism. J Neurochem 40:1013-1018.

Ibrahim MZM (1975) Glycogen and its related enzymes of metabolism in the central nervous system. Adv Anat Embryol Cell Biol 52:1-85.

Kocher M (1990) Metabolic and hemodynamic activation of postischemic rat brain by cortical spreading depression. J Cereb Blood Flow Metab 10:564-571.

Koizumi J (1974) Glycogen in the central nervous system. Prog Histochem $6: 1-35$.
Krivánek J (1961) Some metabolic changes accompanying Leão's spreading depression. J Neurochem 6:183-189.

Lauritzen M, Hansen A, Kronberg D, Wieloch T (1990) Cortical spreading depression is associated with arachidonic acid accumulation and preservation of energy charge. J Cereb Blood Flow Metab 10:115-122.

Leão AAP (1944) Pial circulation and spreading depression of activity in the cerebral cortex. J Neurophysiol 7:391-396.

Leniger-Follert E, Hossmann K-A (1979) Simultaneous measurements of microflow and evoked potentials in the somatomotor cortex of the cat brain during specific sensory activation. Pfluegers Arch 380:8589.

Lewis LD, Ljunggren B, Norberg K, Siesjö BK (1974) Changes in carbohydrate substrates, amino acids and ammonia in the brain during insulin-induced hypoglycemia. J Neurochem 23:659-671.

Ljunggren B, Schutz H, Siesjö BK (1974) Changes in energy state and acid-base parameters of the rat brain during compression ischemia. Brain Res 74:277-289.

Lowry OH, Passonneau JV, Hasselberger FX, Schulz DW (1964) Effect of ischemia on known substrates and cofactors of the glycolytic pathway in brain. J Biol Chem 239:18-30.

Lund-Andersen H (1979) Transport of glucose from blood to brain. Physiol Rev 59:305-352.

Mason GF, Behar KL, Rothman DL, Shulman RG (1992) NMR determination of intracerebral glucose concentration and transport kinetics in rat brain. J Cereb Blood Flow Metab 12:448-455.

Norberg K, Siesjö BK (1976) Oxidative metabolism of the cerebral cortex of the rat in severe insulin-induced hypoglycaemia. J Neurochem 26:345-352.

Pardridge WM (1983) Brain metabolism: a perspective from the bloodbrain barrier. Physiol Rev 63:1481-1535.

Pelligrino DA, Segil LJ, Albrecht RF (1990) Brain glucose utilization and transport and cortical function in chronic vs acute hypoglycemia. Am J Physiol 259:E729-E735.

Pulsinelli WA, Levy DE, Duffy TE (1982) Regional cerebral blood flow and glucose metabolism following transient forebrain ischemia. Ann Neurol 11:499-509.

Roberts JEL, Sick TJ (1992) Glucose enhances recovery of potassium ion homeostasis and synaptic excitability after anoxia in hippocampal slices. Brain Res 570:225-230.

Robinson P, Rapoport SI (1986) Glucose transport and metabolism in the brain. Am J Physiol 250:R127-R136.

Sagar SM, Sharp FR, Swanson RA (1987) The regional distribution of glycogen in rat brain fixed by microwave irradiation. Brain Res 417:172-174.

Scheller F, Kirstein D, Kirstein L, Schubert F, Wollenberger U, Olsson B, Gorton L, Johansson G (1987) Enzyme electrodes and their application. Philos Trans R Soc Lond [Biol] 316:85-93.

Schurr A, West CA, Reid KH, Tseng MT, Reiss SJ, Rigor BM (1987) Increased glucose improves recovery of neuronal function after cerebral hypoxia in vitro. Brain Res 421:135-139.

Shinohara M, Dollinger B, Brown G, Rapoport S, Sokoloff L (1979) Cerebral glucose utilization: local changes during and after recovery from spreading depression. Science 203:188-190.

Siemkowicz E, Hansen AJ (1981) Brain extracellular ion composition and EEG activity following 10 minutes ischemia in normo- and hyperglycemic rats. Stroke 12:236-240.

Siemkowicz E, Hansen AJ, Gjedde A (1982) Hyperglycemic ischemia of the brain: the effect of post-ischemic insulin on metabolic state. Brain Res 243:386-390.

Siesjö BK (1978) Brain energy metabolism. New York: Wiley.

Silver IA (1976) A microglucose electrode. In: Ion and enzyme electrodes (Kessler M, ed), pp 189-192. Munich: Urban and Schwarzenberg.

Silver IA, Erecińska M (1990) Intracellular and extracellular changes of $\left[\mathrm{Ca}^{2+}\right]$ in hypoxia and ischemia in rat brain in vivo. J Gen Physiol 95:837-866

Silver IA, Erecińska M (1992) Ion homeostasis in rat brain in vivo: intra- and extracellular $\left[\mathrm{Ca}^{2+}\right]$ and $\left[\mathrm{H}^{+}\right]$in the hippocampus during recovery from short-term, transient ischemia. J Cereb Blood Flow Metab 12:759-772.

Sokoloff L (1981) Localization of functional activity in the central nervous system by measurement of glucose utilization with radioactive deoxyglucose. J Cereb Blood Flow Metab 1:7-36.

Stosseck K, Lübbers DW, Cottin N (1974) Determination of local 
blood flow (microflow) by electrochemically generated hydrogen. Pfluegers Arch Gesamte Physiol Menschen Tiere 348:225-238.

Tews JK, Carter SH, Stone WE (1965) Chemical changes in the brain during insulin hypoglycemia and recovery. J Neurochem 12:679-693.

Trinder $\mathbf{P}$ (1969) Determination of glucose in blood using glucose oxidase with an alternative oxygen acceptor. Ann Clin Biochem 6:24 27.

van der Kuil JHF, Korf J (1991) On-line monitoring of extracellular brain glucose using microdialysis and a NADPH-linked enzymatic assay. J Neurochem 57:648-654.
Van Harreveld A, Ochs S (1957) Electrical and vascular concomitants of spreading depression. Am J Physiol 189:159-166.

Watanabe H, Passonneau JV (1973) Factors affecting the turnover of cerebral glycogen and limit dextrin in vivo. J Neurochem 20:15431554.

Welsh FA, Ginsberg MD, Rieder W, Budd WW (1980) Deleterious effect of glucose pretreatment on recovery from diffuse cerebral ischemia in the cat. II. Regional metabolite levels. Stroke 11:355-363. 